\title{
Noninvasive Whole-Body Imaging of \\ Phosphatidylethanolamine as a Cell Death Marker Using 99mTc-Duramycin During TNF-Induced SIRS
}

\author{
Tinneke Delvaeye ${ }^{1-3}$, Leonie wyffels ${ }^{4}$, Steven Deleye ${ }^{4}$, Kelly Lemeire ${ }^{1,2}$, Amanda Gonçalves ${ }^{1,2,5}$, Elke Decrock ${ }^{3}$, \\ Steven Staelens ${ }^{4}$, Luc Leybaert*3, Peter Vandenabeele*1,2, and Dmitri V. Krysko*6 \\ ${ }^{1}$ VIB Center for Inflammation Research, Ghent, Belgium; ${ }^{2}$ Department of Biomedical Molecular Biology, Ghent University, Ghent, \\ Belgium; ${ }^{3}$ Physiology Group, Department of Basic Medical Sciences, Ghent University, Ghent, Belgium; ${ }^{4}$ Molecular Imaging Center \\ Antwerp, University of Antwerp, Wilrijk, Belgium; ${ }^{5}$ VIB BioImaging Core, Ghent, Belgium; and ${ }^{6}$ Anatomy and Embryology Group, \\ Department of Basic Medical Sciences, Ghent University, Ghent, Belgium
}

Systemic inflammatory response syndrome (SIRS) is an inflammatory state affecting the whole body. It is associated with the presence of pro- and antiinflammatory cytokines in serum, including tumor necrosis factor (TNF). TNF has multiple effects and leads to cytokine production, leukocyte infiltration, and blood pressure reduction and coagulation, thereby contributing to tissue damage and organ failure. A sterile mouse model of sepsis, TNF-induced SIRS, was used to visualize the temporal and spatial distribution of damage in susceptible tissues during SIRS. For this, a radiopharmaceutical agent, $99 \mathrm{~m} T \mathrm{c}$-duramycin, that binds to exposed phosphatidylethanolamine on dying cells was longitudinally visualized using SPECT/CT imaging. Methods: C57BL/6J mice were challenged with intravenous injections of murine TNF or vehicle, and necrostatin-1 was used to interfere with cell death. Two hours after vehicle or TNF treatment, mice received ${ }^{99 m T c-d u r a m y c i n ~ i n t r a v e-~}$ nously (35.44 $\pm 3.80 \mathrm{MBq})$. Static whole-body 99mTc-duramycin SPECT/CT imaging was performed 2, 4 , and $6 \mathrm{~h}$ after tracer injection. Tracer uptake in different organs was quantified by volume-ofinterest analysis using PMOD software and expressed as SUV $\mathrm{V}_{\text {mean. }}$ After the last scan, ex vivo biodistribution was performed to validate the SPECT imaging data. Lastly, terminal deoxynucleotidyl-transferase-mediated deoxyuridine triphosphate nick-end labeling (TUNEL) staining was performed to correlate the obtained results to cell death. Results: An increased ${ }^{99 m}$ Tc-duramycin uptake was detected in mice injected with TNF, when compared with control mice, in lungs $(0.55 \pm 0.1$ vs. $0.34 \pm 0.05)$, intestine $(0.75 \pm 0.13$ vs. $0.56 \pm 0.1)$, and liver ( $1.03 \pm 0.14$ vs. $0.64 \pm 0.04) 4 \mathrm{~h}$ after TNF and remained significantly elevated until $8 \mathrm{~h}$ after TNF. The imaging results were consistent with ex vivo $y$-counting results. Significantly increased levels of tissue damage were detected via TUNEL staining in the lungs and intestine of mice injected with TNF. Interestingly, necrostatin-1 pretreatment conferred protection against lethal SIRS and reduced the ${ }^{99 m}$ Tc-duramycin uptake in the lungs $8 \mathrm{~h}$ after TNF (SUV, $0.32 \pm 0.1$ vs. $0.51 \pm 0.15$ ). Conclusion: This study demonstrated that noninvasive $99 \mathrm{mTc}$-duramycin SPECT imaging

Received Nov. 21, 2017; revision accepted Jan. 16, 2018.

For correspondence or reprints contact either of the following:

Dmitri V. Krysko, Department of Basic Medical Sciences, Ghent University,

Corneel Heymanslaan 10, 4B3, 9000 Ghent, Belgium.

E-mail: dmitri.krysko@ugent.be

Leonie wyffels, Department of Nuclear Medicine, University Hospital Antwerp, Wilrijkstraat 10, 2650 Edegem, Belgium.

Email: leonie.wyffels@uza.be

${ }^{*}$ Contributed equally to this work.

Published online Feb. 1, 2018.

COPYRIGHT (c) 2018 by the Society of Nuclear Medicine and Molecular Imaging. can be used to characterize temporal and spatial kinetics of injury and cell death in susceptible tissues during TNF-induced SIRS, making it useful for global, whole-body assessment of tissue damage during diseases associated with inflammation and injury.

Key Words: necrostatin-1; damage; sepsis; 99mTc-duramycin; SPECT imaging

J Nucl Med 2018; 59:1140-1145

DOI: 10.2967/jnumed.117.205815

\section{A}

cute systemic inflammation occurs in many severe conditions, such as sepsis, severe burns, hemorrhage, and ischemia and reperfusion, and serves to remove invading microorganisms and to restore homeostasis $(1,2)$. However, an unbalanced and uncontrolled regulation of the inflammatory response causes systemic inflammatory response syndrome (SIRS) (3), which correlates with a cytokine storm in the circulation, that is, production and secretion of proinflammatory cytokines, including tumor necrosis factor (TNF) (4). Subsequently, an amplification in cytokine release, leukocyte infiltration, microvascular dysfunction, consecutive hypotension, and coagulation leads to oxygen deprivation in different tissues, which induces cell death and damage in many organs, a state also known as multiple organ injury (5). Various experimental models exist to mimic SIRS in vivo, of which in one TNF is injected intravenously, thereby mimicking the acute hyperinflammatory phase of SIRS. TNF-induced SIRS is a well-known commonly used mouse model of sterile sepsis (6-8), which was also used in this study.

Receptor-interacting protein kinases (RIPKs), which are implicated in apoptosis, and in a regulated form of necrosis (also known as necroptosis (9)), were previously reported to play a crucial role in the TNF-induced SIRS pathology $(6,8,10)$. Depending on the cell death modality, dead or dying cells manifest different characteristics, ranging from membrane blebbing in apoptosis to complete cell disruption in necroptosis. Intriguingly, both apoptotic and necroptotic cells display a similar loss of lipid asymmetry in their plasma membranes, by translocation of different phospholipids from the inner plasma membrane leaflet to the outer plasma membrane leaflet (11). The best-studied flipped phospholipids in the context of cell death are phosphatidylserine (12-14) and phosphatidylethanolamine $(15,16)$, which thus represent interesting targets for cell death 
visualization, during, for example, SIRS or ischemia and reperfusion. Phosphatidylserine and phosphatidylethanolamine can be imaged through selective binding by annexin-V (17-19) and duramycin $(15,20)$, respectively, both of which can be bioconjugated or labeled. Because the binding specificity of annexin- $\mathrm{V}$ to phosphatidylserine disappears in the absence of $\mathrm{Ca}^{2+}(21)$, and high abdominal background levels complicate annexin-based image analysis, the specific binding of the lantibiotic probe duramycin to phosphatidylethanolamine pops up as an attractive alternative. Because of its high affinity to phosphatidylethanolamine, its stable and rigid character, and its lack of cross-reactivity with other phospholipids, it is an easy and specific tool to use in in vivo imaging studies $(15,22)$. Because of the known limitations associated with avidin-biotin systems (background) and green fluorescent protein (poor light penetration through tissues), ${ }^{99 \mathrm{~m}} \mathrm{Tc}$ is one of the most widely used radiolabels for duramycin. As such, ${ }^{99 \mathrm{~m} T c-d u r a m y-}$ cin has been applied extensively to detect dead or dying cells in vivo, for example, in atherosclerotic plaques (23), in tumors challenged by different chemotherapy or radiotherapy schemes $(24,25)$, or in different stages of lung injury (26), where it can be useful in the characterization of new cell death biomarkers.

The aim of this study was to characterize the temporal and spatial kinetics of injury in susceptible tissues during TNFinduced SIRS. Therefore, we followed ${ }^{99 \mathrm{~m}} \mathrm{Tc}$-duramycin-induced cell death in TNF-injected mice by using noninvasive SPECT imaging. RIPK1 blocking studies, ex vivo biodistribution studies, and terminal deoxynucleotidyl-transferase-mediated deoxyuridine triphosphate nick-end labeling (TUNEL) staining were included to validate the imaging data and to confirm the specificity of ${ }^{99 \mathrm{~m}} \mathrm{Tc}-$ duramycin in detecting RIPK1-dependent cell death during SIRS. We found a TNF-induced increase in ${ }^{99 m} \mathrm{Tc}$-duramycin uptake in the lungs, intestine, and liver, and we characterized the lungs as a potential target for RIPK1-mediated cell death. Furthermore, TUNEL images of the lungs confirmed the decrease in the degree of cell death after administration of a RIPK1 kinase inhibitor. Noninvasive imaging of cell death during SIRS could be helpful to screen different pathologic sites or to assess the extent of tissue damage, making it an interesting tool for future clinical studies.

\section{MATERIALS AND METHODS}

\section{Mice}

Male C57BL/6J wild-type mice were purchased from Janvier. All mice were bred in specific pathogen-free conditions, were used at the age of 8-10 wk, and were housed in air-conditioned, temperaturecontrolled rooms with 14-h/10-h light/dark cycles. Food and water were provided ad libitum. All experiments were organized according to institutional, national, and European animal regulations. All experiments were approved by the animal ethics committees at Antwerp University (ECD 2015-41) and Ghent University (ECD 2016-029).

\section{TNF-Induced Lethal Shock: Monitoring and Sampling}

Necrostatin-1 (480065; Merck) was dissolved in dimethylsulfoxide, further diluted in endotoxin-free Dulbecco phosphate-buffered saline (Sigma-Aldrich), and injected intravenously in a $200 \mu \mathrm{L}$ volume at 6.25 $\mathrm{mg} / \mathrm{kg}, 15 \mathrm{~min}$ before intravenous injection of murine TNF $(10 \mu \mathrm{g} / 20 \mathrm{~g})$ in $200 \mu \mathrm{L}$ of endotoxin-free phosphate-buffered saline ( $\mathrm{pH}$ 6.8). Control mice received an equal amount of Dulbecco phosphate-buffered saline (vehicle) intravenously 15 min before challenge with TNF. Recombinant mouse TNF was produced in Escherichia coli and purified (>95\%) in the Protein Service Facility (IRC), with a biologic activity of $4.15 \times$ $10^{9} \mathrm{IU} / \mathrm{mg}$ (determined with MTT [3-[4,5-dimethylthiazole-2-yl]-2,5- diphenyltetrazolium bromide] assay). Two hours after TNF injection, $200 \mu \mathrm{L}$ of purified ${ }^{99 \mathrm{~m}} \mathrm{Tc}$-duramycin $(35.44 \pm 3.80 \mathrm{MBq})$ were intravenously injected. Body temperatures were monitored with an electric thermometer (Model 1; Comark Electronics) until $8 \mathrm{~h}$ after TNF injection.

\section{Radiolabeling of Duramycin}

A kit (kindly provided by Molecular Targeting Technologies, Inc.) was used to prepare ${ }^{99 \mathrm{~m}} \mathrm{Tc}$-duramycin. A $1,480-\mathrm{MBq}$ quantity of ${ }^{99 \mathrm{~m}} \mathrm{Tc}-$ pertechnetate in $500 \mu \mathrm{L}$ of saline was added to the kit and heated for $20 \mathrm{~min}$ at $80^{\circ} \mathrm{C}$. The obtained ${ }^{99 \mathrm{~m}} \mathrm{Tc}$-duramycin was purified using high-performance liquid chromatography as described previously (25).

\section{In Vivo Small-Animal SPECT/CT Imaging and Ex Vivo Biodistribution Studies}

At 2, 4, and $6 \mathrm{~h}$ after ${ }^{99 \mathrm{~m}} \mathrm{Tc}$-duramycin injection, 20-min static whole-body images were acquired, followed by 10-min whole-body high-resolution CT scans, using a small-animal SPECT/CT scanner (VECTor/CT; MILabs) equipped with a rat multipinhole SPECT collimator. The mice were anesthetized with isoflurane $(\sim 2 \%)$, and body temperature was maintained using a heating pad. SPECT images were reconstructed with ordered-subsets expectation maximization (10 iterations, 16 subsets) and a $1.2-\mathrm{mm}^{3}$ voxel size. A $20 \%$ energy window centered on the $140-\mathrm{keV}$ photopeak was used. Volumes of interest were drawn on the SPECT/CT images using PMOD software (PMOD Technologies) for intestines, lungs, liver, and kidneys. ${ }^{99 \mathrm{~m}} \mathrm{Tc}$-duramycin uptake was quantified as $\mathrm{SUV}_{\text {mean }}$ using the formula [average radioactivity concentration (in $\mathrm{kBq} / \mathrm{cm}^{3}$ ) in the volumes of interest]/[decaycorrected amount of injected activity (in $\mathrm{kBq}$ )/body weight ( $\mathrm{g}$ )].

After the last static scan ( $8 \mathrm{~h}$ after TNF injection or $6 \mathrm{~h}$ after tracer injection), the mice were euthanized by cervical dislocation under isoflurane anesthesia, for ex vivo biodistribution. Blood and different organs and tissues were harvested, rinsed in Dulbecco phosphatebuffered saline, blotted dry, and weighed, and the radioactivity in the samples was counted by an automatic $\gamma$-counter (Wizard2 2480; Perkin Elmer). Uptake of ${ }^{99 \mathrm{~m} T c-d u r a m y c i n ~ w a s ~ d e c a y-c o r r e c t e d ~ a n d ~ p r e s e n t e d ~}$ as percentage injected dose per gram.

\section{Immunohistochemistry}

Histologic samples were collected $6 \mathrm{~h}$ after TNF injection and evaluated on paraffin sections. Cell death was identified by TUNEL (TMR in situ cell death detection kit; Sigma-Aldrich) and counterstained with DAPI (4',6-diamidino-2-phenylindole; Thermo Fisher Scientific). Micrographs were acquired using an Axioscan Z.1 slide scanner (Carl Zeiss) at $\times 20$ magnification and an ORCA Flash4 camera (Hamamatsu Photonics) while illuminated by an HXP 120-V light source. Histologic data were analyzed using Volocity (PerkinElmer) and QuPath (GitHub) software.

\section{Statistical Analysis}

Statistical analysis was performed with GraphPad Prism software (version 7.0). One-way ANOVA or 2-way repeated-measures ANOVA was used for multiple comparisons between several groups, followed by a Bonferroni test. A $P$ level of less than 0.05 was considered statistically significant.

\section{RESULTS}

\section{TNF-Induced SIRS Leads to Higher In Vivo Uptake of 99mTc-Duramycin}

Because TNF-induced SIRS is an acute model, mimicking a cytokine storm and inducing tissue damage only a few hours after TNF is injected (6), we assessed the in vivo uptake of ${ }^{99 \mathrm{~m}} \mathrm{Tc}-$ duramycin at 4,6 , and $8 \mathrm{~h}$ after TNF treatment. TNF led to a 


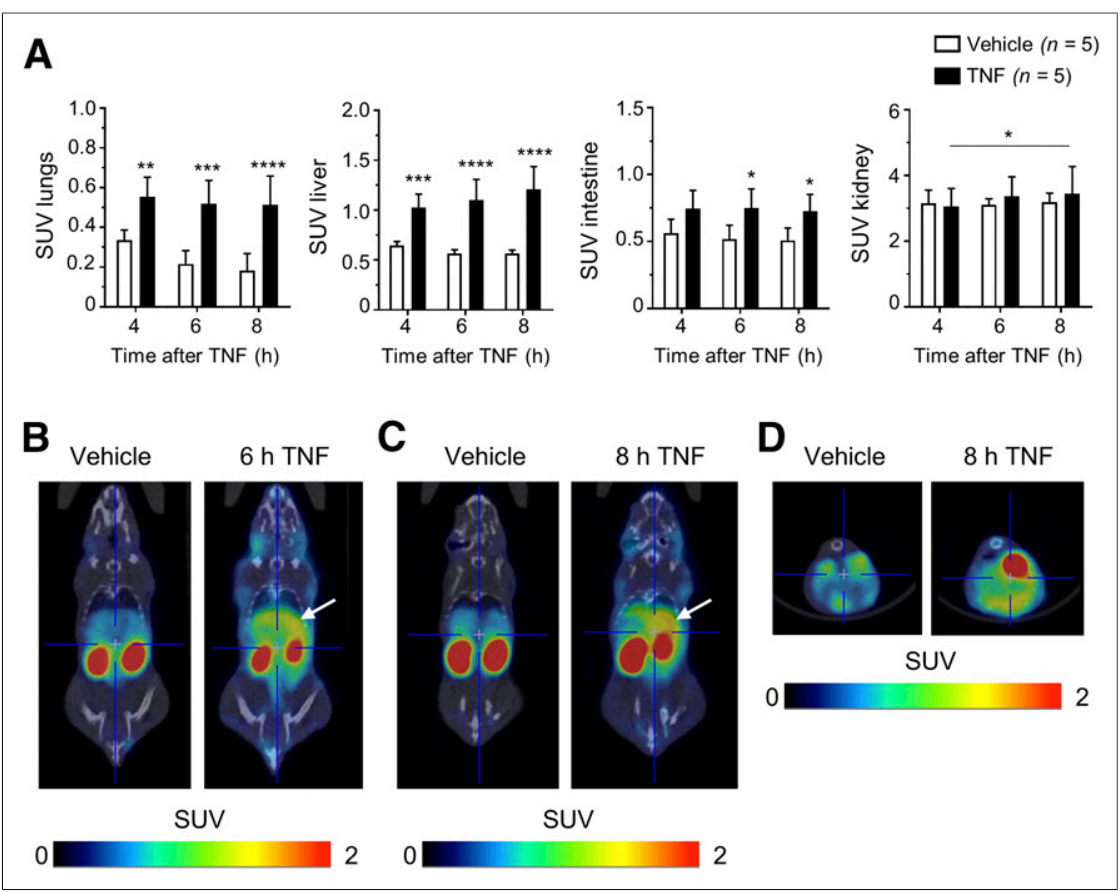

FIGURE 1. Higher uptake of $99 \mathrm{mT}$ C-duramycin after SIRS induction by TNF. Vehicle or TNF was injected $2 \mathrm{~h}$ before ${ }^{99 m T c}$-duramycin. (A) Graphs showing mean \pm SD for 5 animals (each day, 1 animal per group was monitored). ${ }^{\star} P=0.0137$ and 0.0221 for intestine and 0.0158 for kidney. ${ }^{\star \star} P=$ 0.0058. ${ }^{* \star \star} P<0.001 .{ }^{* \star \star \star} P<0.0001$. (B-D) Coronal SPECT/CT images $6 \mathrm{~h}$ (B) or $8 \mathrm{~h}(\mathrm{C})$ after vehicle

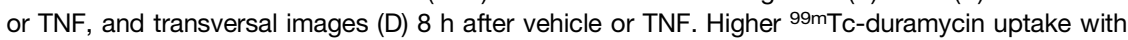
TNF than with vehicle is indicated by arrows.

significantly increased SUV in different organs, including lungs, liver, and intestine, when compared with control mice (Fig. 1A). This increase was detected and maintained at the 3 time points included in this study. The increased uptake of ${ }^{99 \mathrm{~m}} \mathrm{Tc}$-duramycin in lungs, liver, and intestine in TNF-treated mice, compared with vehicle-treated mice, was also visible in the SPECT/CT images generated at 6 and $8 \mathrm{~h}$ after TNF treatment (Figs. 1B-1D). The ex vivo biodistribution data obtained $8 \mathrm{~h}$ after TNF treatment confirmed the increased uptake in lungs, liver, and small intestine, whereas no significant differences in tracer uptake were detected in the other isolated organs and tissues (Fig. 2). The accumulation of radioactivity was highest in kidneys, reflecting normal tracer clearance (Fig. 2) (25). Of note, a significant increase in ${ }^{99 \mathrm{~m}} \mathrm{Tc}-$ duramycin uptake in kidneys was observed $8 \mathrm{~h}$ after TNF treatment $\left(\mathrm{SUV}_{\text {mean }}, 3.4481 \pm 0.82\right)$, when compared with the $4 \mathrm{~h}$ levels ( $\left.\mathrm{SUV}_{\text {mean }}, 3.05913 \pm 0.54\right)$, whereas for the control animals no change in kidney uptake could be detected (Fig. 1A). Nevertheless, because of the high background levels caused by tracer clearance, the kidneys were not further analyzed in this study.

\section{Necrostatin-1 Significantly Blocks In Vivo ${ }^{99 m}$ Tc-Duramycin Uptake in Lungs}

It is known that inhibition of the kinase activity of RIPK1 by necrostatin-1 leads to complete protection against hypothermia and mortality during TNF-induced SIRS (6). Furthermore, a decrease in the release of cytokines, such as interleukin- 6 and interleukin- 1 , and of organ damage parameters, such as alanine aminotransferase, aspartate aminotransferase, and creatine kinase, was observed in the circulation of mice receiving necrostatin-1 pretreatment upon TNF injection (6). Therefore, we were interested in the effect of necrostatin- 1 on ${ }^{99 \mathrm{~m}} \mathrm{Tc}-$ duramycin uptake, to validate the occurrence of RIPK1-mediated cell death during TNFinduced SIRS. Interestingly, a decreased uptake of ${ }^{99 \mathrm{~m}} \mathrm{Tc}$-duramycin was visible in the SPECT/CT images of animals treated with necrostatin-1, compared with the animals receiving vehicle pretreatment upon TNF injection (Fig. 3A). However, after image quantification, inhibition of RIPK1 kinase activity only led to a significant decrease of 99mTc-duramycin uptake in the lungs, $8 \mathrm{~h}$ after TNF treatment (Fig. 3B), whereas no significant differences were observed in any of the other examined organs, that is, intestine and liver (Supplemental Fig. 1; supplemental materials are available at http://jnm. snmjournals.org). To confirm the protective effect of necrostatin-1, rectal body temperatures were monitored at each scanning time point and verified the better outcome upon necrostatin-1 pretreatment, already visible 6 and $8 \mathrm{~h}$ after TNF (Supplemental Fig. 2).

\section{Decreased ${ }^{99 m}$ Tc-Duramycin Uptake in Lungs upon Necrostatin-1 Pretreatment Correlates with Reduced Cell Death}

To validate the reduction in cell death in lungs upon necrostatin-1, we subsequently performed ex vivo TUNEL staining on lung sections $6 \mathrm{~h}$ after TNF injection, with or without pretreatment with necrostatin-1. This time point was chosen because TUNEL positivity was previously shown to be present $6 \mathrm{~h}$ after TNF injection in liver and intestine (6). A significant increase in the percentage of TUNEL-positive cells was observed in the lungs of mice challenged with TNF, whereas necrostatin-1 could significantly protect mice against this increase (Figs. 4A and 4B), suggesting a RIPK1-mediated cell death induction in lungs. These results were in line with the decreased ${ }^{99 \mathrm{~m}} \mathrm{Tc}$-duramycin uptake in the lungs of mice pretreated with necrostatin-1 (Fig. 3). Intriguingly, necrostatin-1 could also protect against cell death induction in ileum, as quantified by TUNEL staining (Fig. 4A), whereas we did not observe any significant effect of necrostatin1 on ${ }^{99 m}$ Tc-duramycin uptake in intestine (Supplemental Fig. 1). Similarly to ex vivo biodistribution data in large intestine

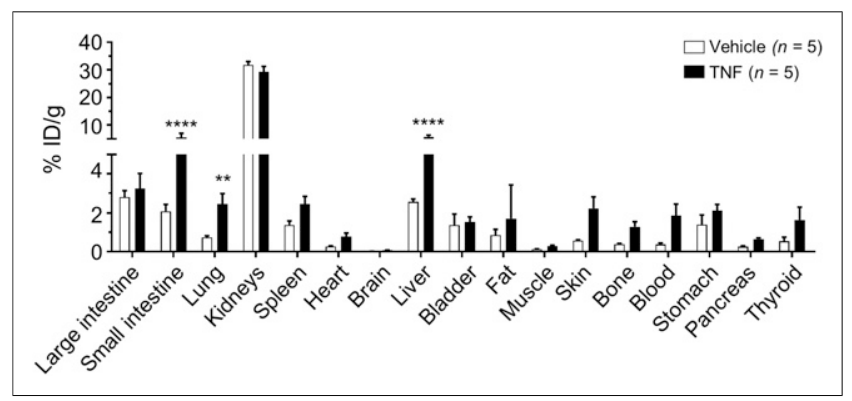

FIGURE 2. Biodistribution of ${ }^{99 \mathrm{mTC}} \mathrm{T}-$ duramycin $6 \mathrm{~h}$ after tracer injection and $8 \mathrm{~h}$ after TNF injection. Vehicle or TNF was injected $2 \mathrm{~h}$ before ${ }^{99 m} \mathrm{mc}$-duramycin. Data are mean \pm SD percentage injected dose per gram (\% ID/g) for 5 animals (each day, 1 animal per group was monitored) $8 \mathrm{~h}$ after injection of vehicle or TNF. ${ }^{\star \star} P=0.002$. ${ }^{\star \star \star \star} P<0.0001$. 


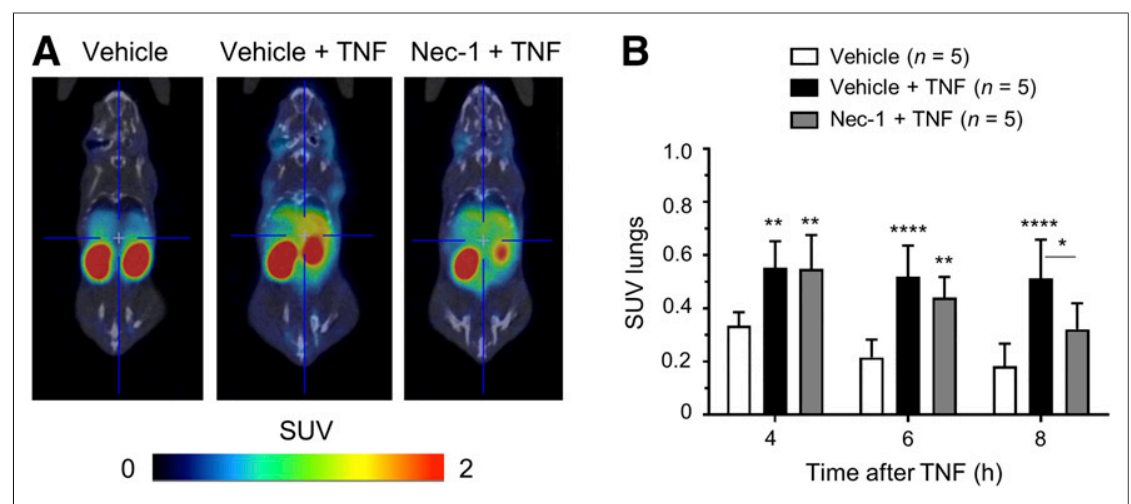

FIGURE 3. Blocking of ${ }^{99 m}$ Tc-duramycin uptake in lungs by pretreatment with necrostatin-1 (Nec-1) 15 min before TNF injection. (A) Coronal SPECT/CT images $8 \mathrm{~h}$ after injection of vehicle, vehicle plus TNF, or necrostatin-1 (Nec-1) plus TNF. (B) Graphs showing mean \pm SD for 5 animals (each day, 1 animal per group was monitored). ${ }^{\star} P=0.0128$. ${ }^{\star \star} P=0.0041,0.0051$, and 0.0032 . ${ }^{\star \star \star \star} P<0.0001$.

(Fig. 2), no significant increase in cell death induction was visible in colon on TUNEL quantification (Fig. 4A).

\section{DISCUSSION}

Our results illustrate that noninvasive whole-body imaging of cell death during SIRS might be helpful to identify damaged tissues and organs throughout the whole body. In the SPECT imaging study, we were able to pinpoint 3 different organs at risk during TNF-induced SIRS, namely lungs, small intestine, and liver. The increase in ${ }^{99 \mathrm{~m}} \mathrm{Tc}$-duramycin uptake in these organs was obvious $4 \mathrm{~h}$ after TNF injection and was maintained until the last measurement, $8 \mathrm{~h}$ after TNF. Ex vivo biodistribution studies using $\gamma$-counting confirmed these observations. Next, we identified the lungs as a possible target for RIPK1-mediated cell death, as necrostatin-1 could significantly reduce lung uptake of ${ }^{99 \mathrm{~m}} \mathrm{Tc}-$ duramycin, as well as the number of dying or dead cells as revealed by TUNEL staining. Altogether, our results demonstrated that $99 \mathrm{~m}$ Tc-duramycin SPECT imaging can allow temporal and spatial imaging of damage in susceptible organs during TNFinduced SIRS, and potentially during other inflammatory diseases associated with cell death dynamics, making it an attractive tool for future clinical studies.

${ }^{99 m}$ Tc-duramycin has been previously used in different in vivo studies analyzing cell death occurrence $(20,25,27)$. Here, we applied it to follow damage induction in a sterile mouse model of sepsis. Our data illustrate the susceptibility of 3 different organs toward cell death induction during TNF-induced SIRS, namely lungs, small intestine, and liver (Figs. 1A and 4). During SIRS and septic shock, these organs are indeed known to be vulnerable to increased damage, eventually leading to multiple organ failure (28). Duprez et al. demonstrated increases in TUNEL-positive cells at the level of ileum and liver during TNF-induced SIRS, which was also confirmed in our study (6). Furthermore, they analyzed different inflammatory cytokines (interleukin-6, interleukin-1) and organ damage parameters in circulation, such as aspartate aminotransferase and alanine aminotransferase (liver), creatine kinase (heart and kidney), and lactate dehydrogenase (overall tissue damage), and found increased levels upon TNF injection. Additionally, they and others showed the involvement in the SIRS pathology of RIPK1 $(6,8)$, a kinase known to contribute to apoptosis and a regulated form of necrosis: necroptosis.
Therefore, we aimed to examine the contribution of RIPK1-mediated cell death during SIRS via prophylactic administration of necrostatin-1, a kinase inhibitor of RIPK1 (6). Interestingly, upon administration of necrostatin-1, we found a significant decrease in ${ }^{99 \mathrm{~m}} \mathrm{Tc}$-duramycin uptake in the lungs after TNF injection (Fig. 3B). These data are in line with previous observations showing that necrostatin-1 could significantly protect against remote lung injury caused by circulating damage-associated molecular patterns and proinflammatory mediators upon necrotic kidney transplants (29). Since Zhao et al. characterized parthanatos, a poly(adenosine diphosphate-ribose) polymerase 1-dependent form of cell death, and necroptosis as the main cell death pathways leading to remote lung injury (29), it is conceivable that also during TNF-induced SIRS, different cell death pathways might contribute to the pathology. Hence, the unchanged levels

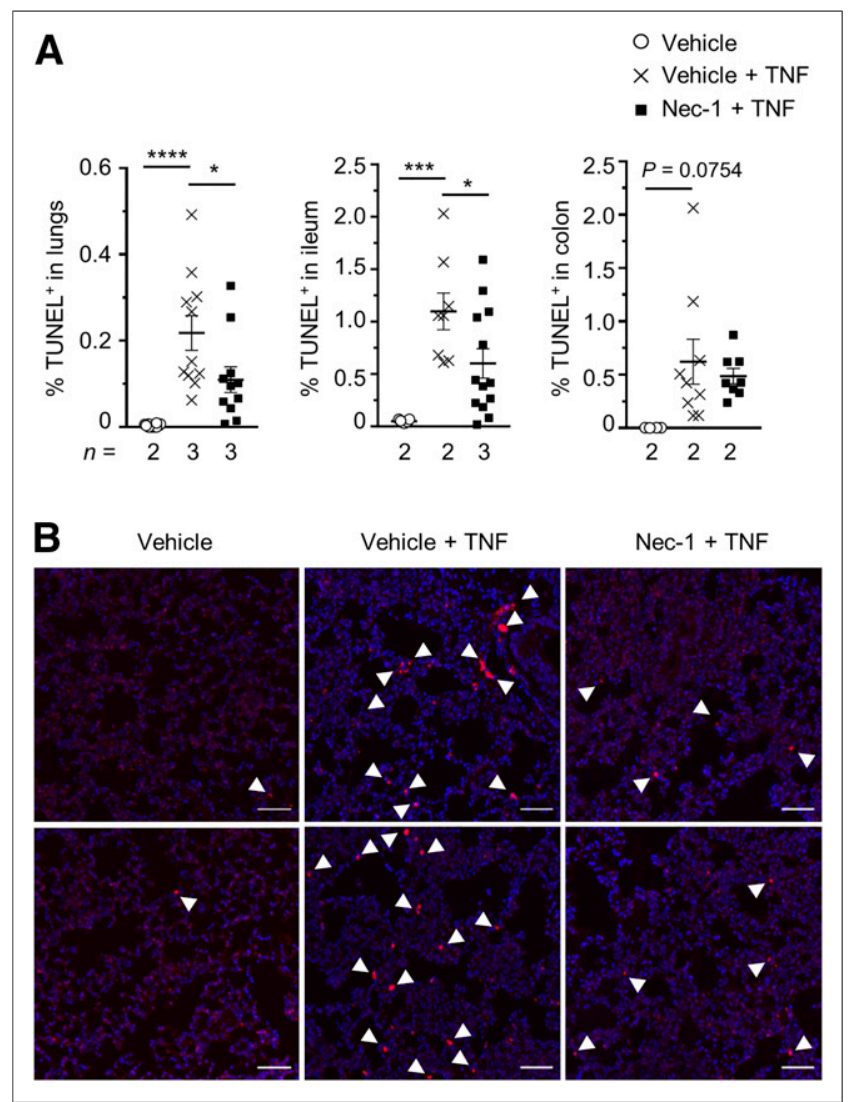

FIGURE 4. Blocking of increase in TUNEL-positive cells by pretreatment with necrostatin-1 (Nec-1) 15 min before TNF injection. After $6 \mathrm{~h}$, organs were isolated and stained for TUNEL positivity. (A) Ratio of TUNEL-positive cells to all DAPI-positive cells. Each data point corresponds to 1 of $3-4$ sections that were taken per organ per mouse; $n=$ total number of mice per group; error bars are SEM from 1 experiment. ${ }^{\star} P=0.0369$ for lungs and 0.0473 for ileum. ${ }^{\star \star \star} P<0.001$. ${ }^{\star \star \star \star} P<0.0001$. (B) Lung sections from mice treated with vehicle $(n=2)$, vehicle plus TNF $(n=3)$, or Nec-1 plus TNF $(n=3)$ as analyzed by TUNEL $6 \mathrm{~h}$ after TNF. Scale bar $=50 \mu \mathrm{m}$; arrowheads indicate TUNEL-positive cells. 
of ${ }^{99 m}$ Tc-duramycin uptake in the intestine and liver upon necrostatin1 administration (Supplemental Fig. 1) could be explained by the presence of other cell death pathways involved. Indeed, in the TNFinduced SIRS pathology, the gut was proven susceptible to apoptosis by use of caspase- 3 knockout mice (6), confirming the notion that the presence of different cell death pathways contributes to TNF-induced SIRS.

An important question remaining in our study is why necrostatin-1 affects ${ }^{99 \mathrm{~m}} \mathrm{Tc}$-duramycin uptake only in the lungs and not in other organs, such as ileum, where it was also able to block cell death as quantified by TUNEL positivity. One possible explanation could be the differences between the 2 quantification techniques; during TUNEL analysis, only a few sections are analyzed per organ, whereas the SPECT scanning analysis includes data obtained on the whole-organ level. Also, whereas TUNEL staining is based on detection of DNA fragmentation, ${ }^{99 \mathrm{~m} T c-d u r a m y c i n}$ binds to phosphatidylethanolamine, a phospholipid that is flipped to the outer plasma membrane leaflet when cells are dying or dead. Thus, it is conceivable that the different cell death detection setups (ex vivo vs. in situ) might give different results. With regard to TUNEL as a quantification technique for cell death, it is important to mention that we applied this method solely to confirm our results obtained by ${ }^{99 \mathrm{~m}} \mathrm{Tc}$-duramycin. To distinguish apoptosis-susceptible regions from necroptosis-susceptible regions, a combination of several techniques should be used to correctly characterize the cell death type (30).

In another model of sepsis, known as cecal ligation and puncture, a near-infrared annexin- $\mathrm{V}$ probe, $\mathrm{AV}-750$, was applied to detect susceptible organs during polymicrobial sepsis (31). Surprisingly, the authors found significant uptake of AV-750 $24 \mathrm{~h}$ after cecal ligation and puncture in lymphatic organs such as the thymus, spleen, and liver, with the liver findings corresponding to our findings (31). However, it has to be noted that annexin- $\mathrm{V}$, because of its high abdominal background levels, has less future clinical applicability than duramycin (15). With its low molecular weight, and hence better pharmacokinetic profile, duramycin correlates with lower background signals (15); however, because its clearance occurs mainly in the kidneys, detection of renal cell death is challenging and remains a drawback of its use. Nevertheless, since different pathologies are linked to cell death, and in vivo imaging with, for example, ${ }^{99 \mathrm{~m}} \mathrm{Tc}$-annexin- $\mathrm{V}$, has already been performed in patient studies $(19,32)$, the use of ${ }^{99} \mathrm{~m}$ Tc-duramycin to detect cell death in SIRS remains an attractive alternative to monitor SIRS pathologies and to invest in better treatment guidance.

\section{CONCLUSION}

We confirmed that different organs, namely, lungs, intestine, and liver, are susceptible for phosphatidylethanolamine exposure as a marker of cellular damage during TNF-induced SIRS, as shown by increased ${ }^{99 \mathrm{~m}} \mathrm{Tc}$-duramycin uptake. Furthermore, our study characterized the lungs as a possible target for RIPK1mediated cell death and hence demonstrated the relevance of blocking different cell death proteins, for example, by necrostatin-1, to help in defining the involved cell death pathways during SIRS. Finally, this study demonstrated the usefulness of ${ }^{99 \mathrm{~m} T c-d u r a m y c i n}$ SPECT imaging for spatial and temporal visualization of cell death and damage during SIRS and potentially in other diseases associated with cell death, inflammation, and injury.

\section{DISCLOSURE}

This work was supported by project grants from UGent Special Research Fund (BOF14/GOA/019) and the Fund for Scientific Research Flanders (FWO) $1506218 \mathrm{~N}$ and $1507118 \mathrm{~N}$ to Dmitri Krysko. Research in the Luc Leybaert group is supported by the Fund for Scientific Research, Flanders, Belgium (grant G.0A82.13N); the Interuniversity Attraction Poles Program (grant P7/10); Ghent University (BOF); and the Geneeskundige Stichting Koningin Elisabeth (grant STI.DI2.2017.0004.01). Research in the Peter Vandenabeele group is supported by Belgian grants (Interuniversity Attraction Poles, IAP 7/32), Flemish grants (Research Foundation Flanders: FWO G.0875.11, FWO G.0973.11, FWO G.0A45.12N, FWO G.0787.13N, FWO G.0E04.16N, and FWO G.0C31.14N), Methusalem grants (BOF09/01M00709 and BOF16/MET_V/007), Ghent University grants (MRP and GROUP-ID consortium), a grant from the Foundation Against Cancer (2012-188), and grants from VIB. Tinneke Delvaeye was paid by FWO G.0A54.13N to Dmitri Krysko and Luc Leybaert and a Methusalem grant to Peter Vandenabeele (BOF09/01M00709). Research at Antwerp University was funded by the University of Antwerp and its University Hospital, Antwerp, Belgium, through a postdoctoral research position for Steven Deleye, an assistant professor position for Leonie wyffels, and an associate professor position for Steven Staelens. No other potential conflict of interest relevant to this article was reported.

\section{ACKNOWLEDGMENT}

We thank Caroline Berghmans for her technical assistance.

\section{REFERENCES}

1. Frangogiannis NG, Smith CW, Entman ML. The inflammatory response in myocardial infarction. Cardiovasc Res. 2002;53:31-47.

2. Akira S, Uematsu S, Takeuchi O. Pathogen recognition and innate immunity. Cell. 2006;124:783-801.

3. Davies MG, Hagen P-O. Systemic inflammatory response syndrome. Br J Surg. 1997;84:920-935.

4. Tracey KJ, Beutler B, Lowry SF, et al. Shock and tissue injury induced by recombinant human cachectin. Science. 1986;234:470-474.

5. Angus DC, van der Poll T. Severe sepsis and septic shock. $N$ Engl J Med. 2013;369:840-851.

6. Duprez L, Takahashi N, Van Hauwermeiren F, et al. RIP kinase-dependent necrosis drives lethal systemic inflammatory response syndrome. Immunity. 2011;35: 908-918.

7. Vanden Berghe T, Demon D, Bogaert P, et al. Simultaneous targeting of IL-1 and IL-18 is required for protection against inflammatory and septic shock. Am J Respir Crit Care Med. 2014;189:282-291.

8. Newton K, Dugger DL, Maltzman A, et al. RIPK3 deficiency or catalytically inactive RIPK1 provides greater benefit than MLKL deficiency in mouse models of inflammation and tissue injury. Cell Death Differ. 2016;23:1565-1576.

9. Pasparakis M, Vandenabeele P. Necroptosis and its role in inflammation. Nature. 2015;517:311-320.

10. Moreno-Gonzalez G, Vandenabeele P, Krysko DV. Necroptosis: a novel cell death modality and its potential relevance for critical care medicine. Am J Respir Crit Care Med. 2016;194:415-428.

11. Fadeel B, Xue D. The ins and outs of phospholipid asymmetry in the plasma membrane: roles in health and disease. Crit Rev Biochem Mol Biol. 2009;44: 264-277.

12. Krysko O, de Ridder L, Cornelissen M. Phosphatidylserine exposure during early primary necrosis (oncosis) in JB6 cells as evidenced by immunogold labeling technique. Apoptosis. 2004;9:495-500.

13. Krysko O, Aaes TL, Kagan VE, et al. Necroptotic cell death in anti-cancer therapy. Immunol Rev. 2017;280:207-219. 
14. Gong YN, Guy C, Olauson H, et al. ESCRT-III acts downstream of MLKL to regulate necroptotic cell death and its consequences. Cell. 2017;169:286-300. e216.

15. Elvas F, Stroobants S, Wyffels L. Phosphatidylethanolamine targeting for cell death imaging in early treatment response evaluation and disease diagnosis. Apoptosis. 2017;22:971-987.

16. Emoto K, Toyama-Sorimachi N, Karasuyama H, Inoue K, Umeda M. Exposure of phosphatidylethanolamine on the surface of apoptotic cells. Exp Cell Res. 1997;232:430-434.

17. Blankenberg FG, Katsikis PD, Tait JF, et al. In vivo detection and imaging of phosphatidylserine expression during programmed cell death. Proc Natl Acad Sci USA. 1998;95:6349-6354.

18. Vriens PW, Blankenberg FG, Stoot JH, et al. The use of technetium Tc 99M annexin $\mathrm{V}$ for in vivo imaging of apoptosis during cardiac allograft rejection. J Thorac Cardiovasc Surg. 1998;116:844-853.

19. Hofstra L, Liem IH, Dumont EA, et al. Visualisation of cell death in vivo in patients with acute myocardial infarction. Lancet. 2000;356:209-212.

20. Audi SH, Jacobs ER, Zhao M, Roerig DL, Haworth ST, Clough AV. In vivo detection of hyperoxia-induced pulmonary endothelial cell death using ${ }^{99 \mathrm{~m}} \mathrm{Tc}-$ duramycin. Nucl Med Biol. 2015;42:46-52.

21. Maffey KG, Keil LB, DeBari VA. The influence of lipid composition and divalent cations on annexin V binding to phospholipid mixtures. Ann Clin Lab Sci. 2001;31:85-90.

22. Zhao M, Li Z, Bugenhagen S. ${ }^{99} \mathrm{~m}$ Tc-labeled duramycin as a novel phosphatidylethanolamine-binding molecular probe. J Nucl Med. 2008;49:1345-1352.
23. Liu Z, Larsen BT, Lerman LO, et al. Detection of atherosclerotic plaques in ApoE-deficient mice using ${ }^{99 m}$ Tc-duramycin. Nucl Med Biol. 2016;43:496505 .

24. Elvas F, Vangestel C, Pak K, et al. Early prediction of tumor response to treatment: preclinical validation of ${ }^{99 \mathrm{~m}}$ Tc-duramycin. J Nucl Med. 2016;57:805-811.

25. Elvas F, Vangestel C, Rapic S, et al. Characterization of [ $\left.{ }^{99 \mathrm{~m}} \mathrm{Tc}\right]$ duramycin as a SPECT imaging agent for early assessment of tumor apoptosis. Mol Imaging Biol. 2015;17:838-847.

26. Clough AV, Audi SH, Haworth ST, Roerig DL. Differential lung uptake of ${ }^{99 \mathrm{~m}} \mathrm{Tc}$-hexamethylpropyleneamine oxime and ${ }^{99 \mathrm{~m}} \mathrm{Tc}$-duramycin in the chronic hyperoxia rat model. J Nucl Med. 2012;53:1984-1991.

27. Zhang Y, Stevenson GD, Barber C, et al. Imaging of rat cerebral ischemia-reperfusion injury using ${ }^{99 \mathrm{~m} T c-l a b e l e d ~ d u r a m y c i n . ~ N u c l ~ M e d ~ B i o l . ~ 2013 ; 40: 80-88 . ~}$

28. Singh S, Evans TW. Organ dysfunction during sepsis. Intensive Care Med. 2006;32:349-360.

29. Zhao H, Ning J, Lemaire A, et al. Necroptosis and parthanatos are involved in remote lung injury after receiving ischemic renal allografts in rats. Kidney Int. 2015;87:738-748.

30. Vanden Berghe T, Grootjans S, Goossens V, et al. Determination of apoptotic and necrotic cell death in vitro and in vivo. Methods. 2013;61:117-129.

31. Zou L, Chen HH, Li D, et al. Imaging lymphoid cell death in vivo during polymicrobial sepsis. Crit Care Med. 2015;43:2303-2312.

32. Boersma HH, Kietselaer BLJH, Stolk LML, et al. Past, present and future of Annexin A5: from protein discovery to clinical applications. J Nucl Med. 2005; 46:2035-2050. 